This article is licensed under the Creative Commons Attribution-NonCommercial 4.0 International License (CC BY-NC) (http://www.karger.com/Services/OpenAccessLicense). Usage and distribution for commercial purposes requires written permission.

\title{
Alcoholic Cirrhosis with Zinc and Copper Co-Deficiency
}

\author{
Chanita Unhapipatpong ${ }^{a}$ Daruneewan Warodomwichit ${ }^{a}$ \\ Kumutnart Chanprapaph ${ }^{\text {b }}$
}

aDivision of Nutrition and Biochemical Medicine, Department of Medicine, Faculty of Medicine, Ramathibodi Hospital, Mahidol University, Bangkok, Thailand; bDivision of Dermatology, Department of Medicine, Faculty of Medicine, Ramathibodi Hospital, Mahidol University, Bangkok, Thailand

\section{Keywords}

Acquired acrodermatitis enteropathica - Zinc · Copper - Trace element - Micronutrients ·

Alcoholic cirrhosis

\begin{abstract}
A 54-year-old Thai female with known alcoholic cirrhosis presented with chronic scaly eczematous patches and plaque for over 1 month. Initially, she was treated with oral antibiotics, but the lesions did not improve. The dermatologic examination and history of alcoholic cirrhosis were compatible with zinc deficiency. Moreover, copper deficiency was found together with zinc deficiency. Excessive alcohol consumption can cause zinc and copper co-deficiency. To avoid aggravated copper deficiency after zinc supplementation, copper and zinc were supplemented together in appropriate proportions. On the 2-week follow-up examination, her clinical outcome improved.

(C) 2019 The Author(s)

Published by S. Karger AG, Basel
\end{abstract}


Unhapipatpong et al.: Zinc and Copper Co-Deficiency

\section{Introduction}

Acrodermatitis enteropathica (AE) is a genetic disorder caused by zinc malabsorption. The clinical triads of $\mathrm{AE}$ include acral dermatitis (predominantly the hands, feet, and anogenital area), diffuse non-scarring alopecia, and diarrhea [1]. Zinc is a trace element that acts as coenzyme and is important for structural differentiation including the skin [2]. Acquired zinc deficiency is occasionally reported in the 21st century. Although alcoholic cirrhosis is one of the acquired etiologies of zinc deficiency, excessive alcohol consumption can also cause copper deficiency [3]. To address aggravated copper deficiency from zinc supplementation, zinc and copper were proportionately supplemented. We present the case of a 54-year-old Thai female with acquired acrodermatitis and copper co-deficiency in the context of alcoholic cirrhosis.

\section{Case Report/Case Presentation}

A 54-year-old Thai female with a medical history of alcoholic cirrhosis Child-Pugh B presented with chronic skin rash predominately at the perioral area, perineum, and both legs. She had been consuming one bottle of locally-made rice whiskey per day since the age of 20 . She ceased her alcohol consumption for 1 year and sought medical attention for treatment. She was diagnosed with alcoholic cirrhosis confirmed by ultrasonography and liver function test after common hepatitis virus was excluded. According to her medical history, her medications were diuretics and vitamin B complex. Her eating habit was normal with three meals of main dishes and more than 15 tablespoons per day of various types of protein sources and small meals at night. She did not undertake food restrictions or experience gastrointestinal symptoms such as diarrhea or anorexia but still had a significant weight loss of $5 \mathrm{~kg}$ (57 $\rightarrow 52 \mathrm{~kg}$, $8 \%$ ) within 2 months. The patient developed generalized rash predominately on both legs and feet within 1 month. She also reported similar lesions on the perineum. She had painful swallowing and a declining sense of taste. She returned to the hospital and was diagnosed with chronic eczema with secondary bacterial infection and oral candidiasis; oral antibiotics and antifungal medication were prescribed. The odynophagia improved but the chronic skin lesions were persistent and continued to progress. As a result, she went to the dermatologic outpatient department at Ramathibodi Hospital. On physical examination, she also had cheilitis and atrophic glossitis. The skin lesions were well demarcated, scaly, erythematous, excoriative patches and plaque with flaccid bullae on the perineum extended to the perianal region, left palm, and both legs including soles (Fig. 1). Paronychia and Lindsay's nail were also observed. She had a BMI of 17.8.

Cutaneous biopsy showed psoriasiform dermatitis with confluent parakeratosis, pallor and atrophy of the upper part of the epidermis, and focal dyskeratosis. The findings were compatible with nutritional deficiency. Plasma zinc levels were $32 \mu \mathrm{g} / \mathrm{dL}$. Other laboratory results are shown in Table 1. The etiology of her chronic skin lesion was acquired zinc deficiency. Copper deficiency was also diagnosed from laboratory results at the same time, though no obvious signs of deficiency were observed.

The differential diagnoses for the skin signs are necrolytic migratory erythema (NME), oculo-orogenital syndrome from vitamin $B_{2}, B_{6}$ deficiency [4], and acquired zinc deficiency 
[5]. However, the most probable diagnosis in the patient is acquired zinc deficiency due to her medical history of alcoholic cirrhosis Child-Pugh B. The necrolytic migratory erythema is one of the clinical presentations of glucagonoma syndrome. Glucagon is associated with amino acid metabolism [6], therefore increase of glucagon level reduces amino acids leading to epidermal necrosis. The presence of glucose intolerance or diabetes mellitus, which were found in approximately $80 \%$ of glucagonoma syndrome cases, aided the diagnosis [7]. Decreased serum zinc level was also reported in patients with NME, which also has similar histopathological findings of skin with AE. There are several reports that decreased zinc level may be the pathogenesis of NME due to the improvement of NME after zinc supplement [5, 8]. In case of oculo-orogenital syndrome, the clinical signs might mimic acquired zinc deficiency, which also includes atrophic tongue, angular stomatitis, and dermatitis of the pubic area. However, blepharoconjunctivitis is found only in oculo-orogenital syndrome [4].

On account of zinc deficiency in the setting of alcoholic cirrhosis, zinc supplementation was started along with copper (in the form of trace element solution), vitamin A (in the form of multivitamin), vitamin B complex, and folic acid. Because the oculo-orogenital syndrome from vitamin $\mathrm{B}_{2}$ and $\mathrm{B}_{6}$ deficiency was in differential diagnosis and vitamin $\mathrm{A}$ co-deficiency was considered, the supplements were readily given together. According to individual hospital preparation, there is a specific Ramathibodi trace element solution which contains elemental zinc $13 \mathrm{mg}$ and copper $1.8 \mathrm{mg}$ per $10 \mathrm{~mL}$. On the 2-week follow-up examination, her skin lesions had improved.

\section{Discussion/Conclusion}

$\mathrm{AE}$ is a rare genetic disorder caused by zinc malabsorption. The prevalence of $\mathrm{AE}$ is 1 to 9:1,000,000 [1]. Normally, Zrt- and Irt-like protein (ZIP) is the transporter which facilitates zinc influx across the brush border membrane into cells or forms vesicles to be used in other tissues [2]. Defect in ZIP4 leads to zinc malabsorption resulting in AE. The clinical triads of AE include acral dermatitis (predominately at the face, hands, feet, and anogenital area), diffuse alopecia, and non-bloody diarrhea [9]. Zinc is one of the most important trace elements in the body. The functions are classified into three categories: catalytic, regulatory, and structural functions [10]. Zinc-binding proteins correspond to $10 \%$ of the human proteome [11]. The activities of more than 300 enzymes require zinc serving a catalytic role. In the regulatory role, zinc regulates gene expression by controlling several transcription factors to DNA and cell signaling pathways [2]. Appropriate protein folding also requires zinc. ZAC (zinc-activated channel), which is mostly expressed in basal keratinocytes, is an example of a zinc finger transcription factor [10]. Zinc finger proteins are necessary components for cellular formation, structural differentiation, and maintenance. Patients at risk of zinc deficiency are around fifty percent of the world's population. The World Health Organization (WHO) has stated that the fifth most crucial risk factor for morbidity and mortality is zinc deficiency in developing countries. Therefore, a balanced zinc homeostasis is important for health [12]. The etiologies of zinc deficiency can be divided into low-zinc dietary intake, malabsorption, increased urinary loss, high utilization, and other diseases (HIV/AIDS, cirrhosis, and diabetes) [13]. Inadequate intake and bioavailability of zinc are concerns in developing countries. Plant-based diet con- 
taining high phytic acid content leads to zinc-phytic acid complexes in the intestine and consequently decreases intestinal zinc absorption [14]. Alcohol also impairs intestinal zinc absorption. Beside the gastrointestinal tract's role in maintaining zinc homeostasis, the liver is essential for maintaining zinc through mobilization from rapidly exchanging zinc pools and hypozincemia is associated with zinc transportation into the liver, potentially involving cytokine responsiveness. Hormonal regulatory processes also influence transient fluctuations in plasma zinc level via insulin and other hormones [2]. Nearly $90 \%$ of zinc is found in muscles and bones, while the liver stores about 5\% [15]. Cirrhotic patients, especially with sarcopenia, have lower zinc storage in the liver and muscles. Additionally, severe muscle catabolism and hypoalbuminemia in cirrhotic patients can cause hyperzincuria [12]. Hyperzincuria is caused by low tubular zinc reabsorption and hypoalbuminemia, which results in shift of zinc-binding protein from albumin to other easily excreted ligands, which are lost in urine [2]. Other factors such as inappropriate intake, changes in amino acid and protein metabolism, cytokine effects (mainly IL-6 and endotoxins), portosystemic shunts, and poor hepatic extraction also alter zinc metabolism. This combination increases the risk of cirrhotic patients developing zinc deficiency. Zinc deficiency impacts a diversity of functions of the liver, especially regeneration capacity. Tissue damage is the result of oxidative stress from modulation of selected signaling cascades in the liver and loss of acute-phase response protection leading to vulnerability to hepatitis. The functioning of oxidative sensitive transcription factors that affect cell function, proliferation, and survival is compromised because zinc deficiency alters redox state [12]. Clinical manifestations of zinc deficiency vary depending on the degree of depletion and the onset of deficiency. Due to the functions of zinc, as mentioned above, zinc deficiency results in abnormal skin lesions including acral dermatitis, delayed wound healing, hypogeusia from glossitis, and alopecia. The characteristic of skin lesions in zinc deficiency is a dry, scaly, sharply edged eczematous dermatitis which evolves into erythematous vesicular and pustular crust $[9,16]$. Affected areas usually begin at perioral and anogenital regions, then progress to scalp, hands, feet, trunk, and flexural regions. Mucosal abnormalities present as a red glossy tongue with superimposed oral candidiasis, as observed in this patient. Other signs are diffuse alopecia and paronychia [9]. Main clinical features of liver cirrhosis may be linked to zinc deficiency, including alopecia, testicular atrophy, cerebral dysfunction, poor appetite, altered smell and taste, immune dysfunction, decreased vitamin A and thyroid hormone metabolism, altered protein metabolism, reduced drug elimination capacity, and delayed wound healing [12]. Almost 95\% of zinc is in intracellular components, while plasma zinc constitutes only $0.1 \%$ of total zinc in the whole body. Many conditions may influence the plasma zinc level. However, change in plasma zinc level is preferable to other indicators used to evaluate the whole body zinc status such as plasma zinc flux, alkaline phosphatase, and retinol-binding protein [17]. The cutoff level of zinc deficiency is 70 and $74 \mu \mathrm{g} / \mathrm{dL}$ for fasting females and males, respectively [2]. A standard supplement in adults is approximately $20-40 \mathrm{mg} / \mathrm{day}$ orally [18]. For the zinc deficiency, oral replacement dose is $1-2 \mathrm{mg} / \mathrm{kg} /$ day of elemental zinc or more than two or three times the recommended daily allowance $[9,19,20]$. The higher replacement dose, up to $3 \mathrm{mg} / \mathrm{kg} /$ day of elemental zinc, is used in $\mathrm{AE}$ to overcome the defect of absorption. Higher doses of more than $50 \mathrm{mg} /$ day may be required in patients with severe deficiency from malnutrition or chronic irreversible malabsorptive disorder, but this may lead to gastrointestinal side effects [18]. Zinc replacement is usually prescribed for 3 to 4 months and may be extended up to 6 months if the clinical response is delayed $[19,21]$. The clinical 
improvement is usually presented before significant changes in zinc level [22]. Diarrhea and depression are improved within the first $24 \mathrm{~h}$ of zinc supplement, and the skin lesions cure within 1-2 weeks [9]. When zinc supplement is given within 6 months after the onset of symptoms, the response rate is higher than $70 \%$. Otherwise, the response rate is lower [21]. Zinc supplement can aggravate copper deficiency by causing copper sequestration in enterocyte. Zinc also induces upregulation of metallothionein, which holds copper and prevents copper absorption into the circulation. Therefore, the copper and ceruloplasmin level were monitored in this patient. In the case of zinc deficiency, copper is absorbed more and the copper level should be elevated. Hence, the low copper level together with low ceruloplasmin in the patient with zinc deficiency implies that there is zinc and copper co-deficiency [21]. In previous reports, zinc supplement more than 50-60 mg daily can cause copper deficiency. In this case, we report zinc and copper co-deficiency in a patient with alcoholic cirrhosis. One rare etiology of copper deficiency is excessive alcohol consumption, and the mechanism is still unclear [3]. Other causes such as low copper diet, zinc supplement as copper chelator, enteropathies, prolonged enteral feeding or total parenteral nutrition, or gastric surgery are not found in this patient $[3,23]$. It is recommended that in every $8-15 \mathrm{mg}$ of elemental zinc supplement, $1 \mathrm{mg}$ of copper should be added [24]. The copper supplement is $2-6 \mathrm{mg} / \mathrm{day}$, which is several times more than that of an essential dietary micronutrient requirement $(0.9 \mathrm{mg} / \mathrm{day})$ [3].

\section{Acknowledgement}

We thank the patient and her relatives for allowing the study and report of this case. Special thanks to Dr. Julanon for his strength and encouragement that helped enable this case report. I also thank Ramathibodi Hospital for various opportunities to learn and share.

\section{Statement of Ethics}

According to the World Medical Association Declaration of Helsinki, the patient's daughter has given their written informed consent to publish their case and publication of image.

\section{Disclosure Statement}

The authors have no conflicts of interest to declare.

\section{Funding Sources}

No funding sources. 


\section{Author Contributions}

All authors conceived the study, treated the patient, drafted and revised the manuscript, and approved the final manuscript before submission.

\section{References}

1 Jagadeesan S, Kaliyadan F. Acrodermatitis Enteropathica [Updated 2018 Dec 5] StatPearls [Internet], Treasure Island (FL): StatPearls Publishing; 2018 Jan.

2 Janet CK, Robert JC. Zinc. Modern Nutrition in Health and Disease. Volume 11. United States of America: Lippincott Williams \& Wilkins; 2014. pp. 189-205.

3 Shibazaki S, Uchiyama S, Tsuda K, Taniuchi N. Copper deficiency caused by excessive alcohol consumption. BMJ Case Rep. 2017 Sep;2017:bcr-2017-220921.

4 Friedli A, Saurat JH. Images in clinical medicine. Oculo-orogenital syndrome - a deficiency of vitamins B2 and B6. N Engl J Med. 2004 Mar;350(11):1130.

5 Ogawa Y, Kinoshita M, Shimada S, Kawamura T. Zinc and Skin Disorders. Nutrients. 2018 Feb;10(2):E199.

6 van Beek AP, de Haas ER, van Vloten WA, Lips CJ, Roijers JF, Canninga-van Dijk MR. The glucagonoma syndrome and necrolytic migratory erythema: a clinical review. Eur J Endocrinol. 2004 Nov;151(5):531-7.

7 Vinik A, Pacak K, Feliberti E, Perry RR. Glucagonoma Syndrome. In: De Groot LJ, Chrousos G, Dungan K, Feingold KR, Grossman A, Hershman JM, et al., editors. Endotext. South Dartmouth (MA): MDText.com, Inc.; 2000.

8 Sinclair SA, Reynolds NJ. Necrolytic migratory erythema and zinc deficiency. Br J Dermatol. 1997 May; 136(5):783-5.

9 Klaus W, Richard AJ. Nutrition. Fitzpatrick's Color Atlas \& Synopsis of Clinical Dermatology. Volume 6. McGraw-Hill; 2009. pp. 442-4.

10 Maverakis E, Fung MA, Lynch PJ, Draznin M, Michael DJ, Ruben B, et al. Acrodermatitis enteropathica and an overview of zinc metabolism. J Am Acad Dermatol. 2007 Jan;56(1):116-24.

11 Leoni G, Rosato A, Perozzi G, Murgia C. Zinc proteome interaction network as a model to identify nutrientaffected pathways in human pathologies. Genes Nutr. 2014 Nov;9(6):436.

12 Grüngreiff K. Zinc Deficiency and Liver Diseases-General Observations. SM J Hepat Res Treat. 2016;2(1): 1008.

13 Marovt M, Dragos V. Acquired zinc deficiency: a case report. Acta Dermatovenerol Alp Pannonica Adriat. 2013 Sep;22(3):75-6.

14 Akhtar S. Zinc status in South Asian populations - an update. J Health Popul Nutr. 2013 Jun;31(2):139-49.

15 Mangray S, Zweit J, Puri P. Zinc Deficiency in Cirrhosis: micronutrient for Thought? Dig Dis Sci. 2015 Oct; 60(10):2868-70.

16 Russell RM, Suter PM. Vitamin and Trace Mineral Deficiency and Excess. Harrison's Principles of Internal Medicine. 2015; 19:96e1-10.

17 Lowe NM, Woodhouse LR, Sutherland B, Shames DM, Burri BJ, Abrams SA, et al. Kinetic parameters and plasma zinc concentration correlate well with net loss and gain of zinc from men. J Nutr. 2004 Sep;134(9): 2178-81.

18 Institute of Medicine (US) Panel on Micronutrients. Dietary Reference Intakes for Vitamin A, Vitamin K, Arsenic, Boron, Chromium, Copper, Iodine, Iron, Manganese, Molybdenum, Nickel, Silicon, Vanadium, and Zinc. Washington (DC). US: National Academies Press; 2001. pp. 442-501.

19 Saper RB, Rash R. Zinc: an essential micronutrient. Am Fam Physician. 2009 May;79(9):768-72.

20 Saritha M, Gupta D, Chandrashekar L, Thappa DM, Rajesh NG. Acquired zinc deficiency in an adult female. Indian J Dermatol. 2012 Nov;57(6):492-4.

21 Yanagisawa H. Zinc deficiency and clinical practice - validity of zinc preparations. Yakugaku Zasshi. 2008 Mar;128(3):333-9.

22 Bae-Harboe YS, Solky A, Masterpol KS. A case of acquired Zinc deficiency. Dermatol Online J. 2012 May; 18(5):1.

23 Wazir SM, Ghobrial I. Copper deficiency, a new triad: anemia, leucopenia, and myeloneuropathy. J Community Hosp Intern Med Perspect. 2017 Sep;7(4):265-8. 


\section{Case Reports in Clinical Nutrition}

\begin{tabular}{l|l}
\hline Case Rep Clin Nutr 2019;2:8-15 \\
\hline DOI: 10.1159/000498983 & $\begin{array}{l}\text { @ 2019 The Author(s). Published by S. Karger AG, Basel } \\
\text { www.karger.com/crc }\end{array}$ \\
\hline
\end{tabular}

Unhapipatpong et al.: Zinc and Copper Co-Deficiency

24 Papamargaritis D, Aasheim ET, Sampson B, le Roux CW. Copper, selenium and zinc levels after bariatric surgery in patients recommended to take multivitamin-mineral supplementation. J Trace Elem Med Biol. 2015;31:167-72.
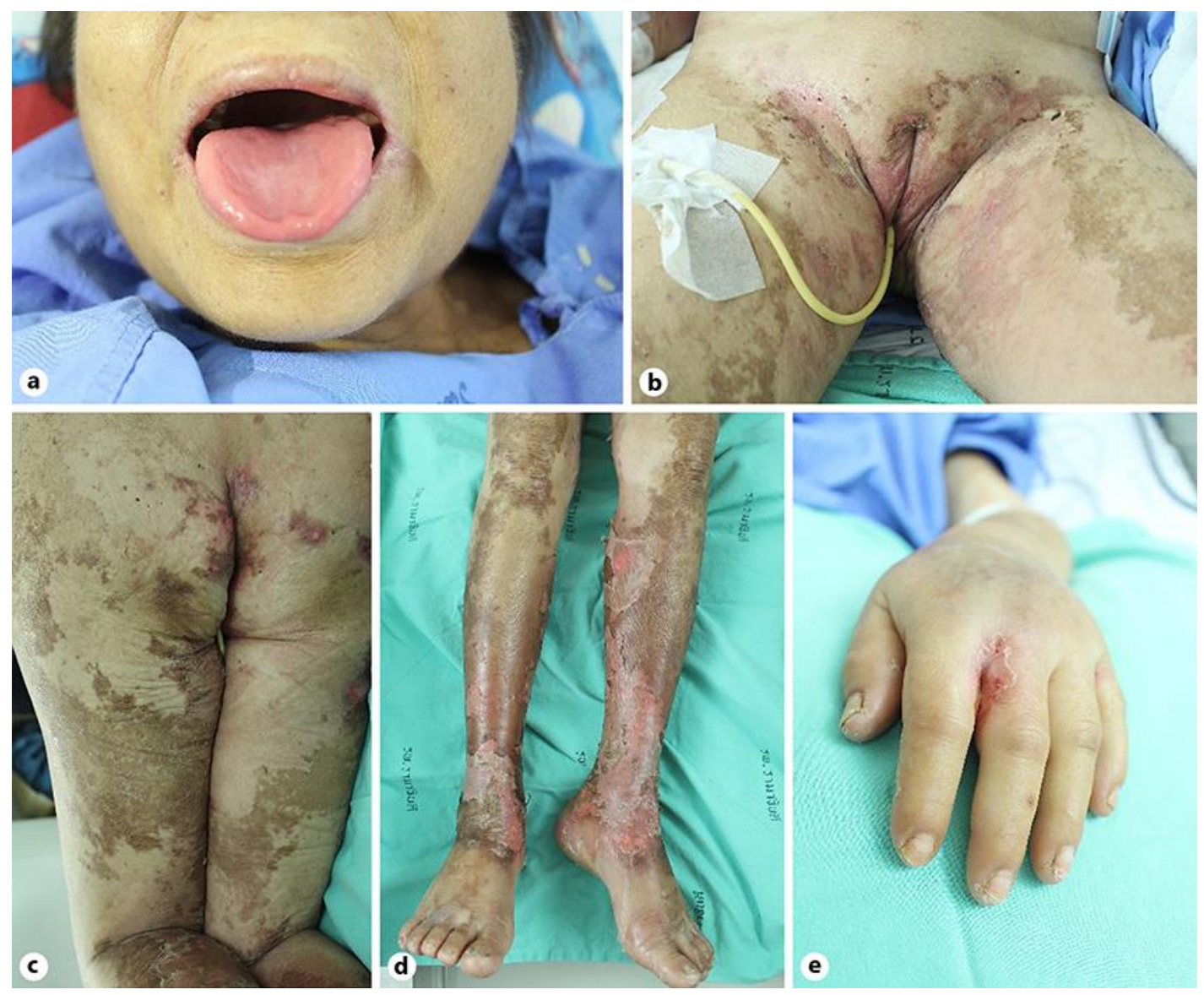

Fig. 1. A 54-year-old Thai female with known alcoholic cirrhosis presented with cheilitis, atrophic glossitis (a), and chronic skin lesions. Dermatologic examination shows well-demarcated, scaly, erythematous, excoriative patches and plaque on the perineum (b) and perianal region (c) extending to both legs (d). There are also similar lesions at the second web space of the left hand and Lindsay's nails (e). 


\section{Case Reports in Clinical Nutrition}

\begin{tabular}{l|l}
\hline Case Rep Clin Nutr 2019;2:8-15 \\
\hline DOI: 10.1159/000498983 & $\begin{array}{l}\text { ( ) 2019 The Author(s). Published by S. Karger AG, Basel } \\
\text { www.karger.com/crc }\end{array}$ \\
\hline
\end{tabular}

Unhapipatpong et al.: Zinc and Copper Co-Deficiency

Table 1. Laboratory values including basic laboratory and micronutrient levels

\begin{tabular}{lll}
\hline & Patient & Normal range \\
\hline Hb, g/dL & 9.8 & $12-13$ \\
Hematocrit, \% & 29.2 & $36-39$ \\
Mean corpuscular volume, fL/red cell & 83.1 & $80-95$ \\
White blood cell, cells/mm ${ }^{3}$ & 9,800 & $4,500-10,700$ \\
Neutrophil, \% & 46.3 & $40-74.5$ \\
Lymphocyte, \% & 40.3 & $16.3-40$ \\
Platelet, cells/mm 3 & 154,000 & $150,000-400,000$ \\
Thiamine pyrophosphate, $\mu \mathrm{g} / \mathrm{L}$ & 105.3 & $28-85$ \\
Zinc, $\mu \mathrm{g} / \mathrm{dL}$ & 32 & $70-120$ \\
ESR, mm/h & 16 & $4-20$ \\
Iron, ng/mL & 56 & $35-150$ \\
TIBC, $\mu \mathrm{g} / \mathrm{dL}$ & 52 & $250-450$ \\
Ferritin, ng/mL & 406.1 & $4.63-204.0$ \\
Copper, $\mu \mathrm{gg} / \mathrm{dL}$ & 40 & $80-155$ \\
Ceruloplasmin, mg/dL & 10.22 & $18-45$ \\
TPP level, $\mu \mathrm{g} / \mathrm{L}$ & 105.3 & $28-85$ \\
B12, $\mathrm{pg} / \mathrm{mL}$ & 1,643 & $187-883$ \\
VDRL (RPR) serum & Non-reactive & Non-reactive \\
TPHA serum & Non-reactive & Non-reactive \\
Aspartate transaminase, U/L & 37 & $5-40$ \\
Alanine transaminase, U/L & 9 & $5-40$ \\
Alkaline phosphatase, U/L & 139 & $40-105$ \\
Cholesterol, mg/dL & 69 & $125-150$ \\
Total protein, g/L & 40.9 & $66-84$ \\
Albumin, g/L & 14.6 & $42-52$ \\
Prothrombin, s & 15.4 & $10-12$ \\
Blood sugar, mg/dL & 51 & \\
\hline
\end{tabular}

